\title{
Drawing behaviour of metal-composite sandwich structures
}

\author{
J. Gresham ${ }^{\text {a,* }}$, W. Cantwell ${ }^{\text {b}}$, M.J. Cardew-Hall ${ }^{\text {a }}$, P. Compston ${ }^{\text {a }}$, S. Kalyanasundaram ${ }^{\text {a }}$ \\ a Department of Engineering, FEIT, Australian National University, Canberra 0200, Australia \\ ${ }^{\mathrm{b}}$ Department of Engineering, University of Liverpool, L69 3GH, United Kingdom
}

Available online 9 June 2006

\begin{abstract}
The drawing behaviour of metal-composite sandwich structures is investigated as a function of the constituent material properties and the process variables of blank preheat temperature and blank-holder force. Materials include three grades of aluminium alloy as the skin layer material and two types of reinforced polypropylene composite as the core layer material. Blank-holder force has a significant effect on the failure mode of the metal-composite system with lower forces resulting in wrinkling as the dominate mode and higher forces resulting in splitting and fracture. Increasing preheat temperature decreases the failure in the composite core however it will increase the severity of wrinkling in the outer flange and sidewall.
\end{abstract}

(C) 2006 Elsevier Ltd. All rights reserved.

Keywords: Metal-composite; Fibre-metal laminate; Drawing; Stamp forming; Wrinkling

\section{Introduction}

Metal-composite or fibre-metal laminate (FML) systems consist of alternating layers of metal and fibre-reinforced composite materials, bonded by an adhesive layer. These hybrid material systems have the potential to tailor the overall mechanical properties of the sandwich structure based on the properties of the constituents. Fibre metal laminates and conventional composite materials have demonstrated success in their usage in low volume aerospace and defence applications due to their excellent fatigue and impact properties [1]. There has been limited use of these hybrid material systems in the high volume industries such as automotive, construction, and consumer goods because of long production times. Stamp forming is a common manufacturing technique used in these industries and provides an efficient manufacturing method to produce products in high volume. Stamp forming of thermo-plastic based FML parts could increase production rates ten to hundred times faster than existing fabrication processes.

\footnotetext{
* Corresponding author. Tel.: +612 61253072; fax: +612 61250506

E-mail address: Joel.Gresham@anu.edu.au (J. Gresham).
}

In the automotive industry, $90 \%$ of deformation of the blank is usually performed in the initial stamping operation and so has the highest impact on part quality. This initial operation is usually dominated by the drawing of the blank into the die cavity. To obtain successful high production of FML systems using stamp forming, an understanding of the drawing behaviour is essential.

The current research on composite and FML forming provide insight into the main variables affecting the formability of such systems. Previous work on channel forming of thermoplastic FML systems [2] demonstrated the effect of preheating the laminate. It was shown that an increase in preheat temperature improves spring-back and reduces damage to the laminate. Cold formed self-reinforced composite based FML produced cracks within the composite layer while the adhesive layer was relatively intact whereas the delamination in a glass-reinforced composite FML was predominantly within the interface [3]. The effects of feedrate, blank-holder force, and tool temperature have been shown in [4] to have an important influence on the formability of channel sections. It was also demonstrated that FML systems could exhibit superior forming characteristics compared to monolithic metals in terms spring back behaviour. This feature is of considerable interest in 
forming automotive body panels where significant time is spent on spring back compensation.

Research on rectangular cup forming of FML systems [5] illustrated failure modes exhibited by different core material types. A glass-fibre reinforced polypropylene core based FML showed extensive wrinkling in the flange while the self-reinforced polypropylene composite core exhibited significant splitting of the aluminium skin layers with no indication of wrinkling. It was shown that pre-heat temperature and core material properties have major influence on the forming characteristics of FML systems.

Kim and Thomson [6] investigated the formability of polymer-metal laminates. They found that at elevated temperatures the rigidity during forming decreases but will improve the spring-back characteristics of the formed part.

Bogaerts [7] studied wrinkle formation and the influence of process variables on the formability of glass-fibre reinforced polypropylene composite. They suggested that high temperatures facilitate desirable shearing behaviour. However, this also increases undesirable fibre slipping. Friedrich and Hou [8] drew conclusions in studying the effects of pre-heat temperature and press closing speed on wrinkle formation. Above a certain closing speed, pre-heat temperature has a dominant influence on wrinkle formation.

The main emphasis of the present study is to investigate the formability of thermo-plastic based FML systems by focusing on its drawing behaviour using hemispherical cup forming. The focus will be to study the effects of the skin and core material selection, preheat temperature and blank-holder force on the drawing behaviour of an FML system, particularly the failure modes. A full factorial experimental array was deemed far too time and resource consuming to be used for the purpose of this study. Instead, the use of a fractional factorial experimental array is used to reduce the experimental set size. This experimental design serves as a screening experiment to identify some of the influences of material properties and process variables on the failure behaviour of an FML.

\section{Experimental procedure}

\subsection{Design of experiment}

The control factors of core and skin material, preheat temperature, and blank-holder force were identified as important variables that may influence the forming behaviour of an FML system. The levels for the control factors were:

1. Composite Core Material (Curv - self-reinforcing polypropylene, Twintex - glass-fibre reinforced polypropylene prepreg).

2. Aluminium Skin Material (2024-O, 2024-T3, 6061-T4).

3. Blank Temperature $(25,60,100,120,140,160)^{\circ} \mathrm{C}$.

4. Blank Holder Force $(2,8,14) \mathrm{kN}$.
Table 1

Screening experiments for each composite core (Curv and Twintex)

\begin{tabular}{rllr}
\hline Run & Temperature $\left({ }^{\circ} \mathrm{C}\right)$ & Skin material & Blank holder-force $(\mathrm{kN})$ \\
\hline 1 & 25 & $2024-\mathrm{O}$ & 2 \\
2 & 25 & $2024-\mathrm{T} 3$ & 8 \\
3 & 25 & $6061-\mathrm{T} 4$ & 14 \\
4 & 60 & $2024-\mathrm{O}$ & 8 \\
5 & 60 & $2024-\mathrm{T} 3$ & 14 \\
6 & 60 & $6061-\mathrm{T} 4$ & 2 \\
7 & 100 & $2024-\mathrm{O}$ & 14 \\
8 & 100 & $2024-\mathrm{T} 3$ & 2 \\
9 & 100 & $6061-\mathrm{T} 4$ & 8 \\
10 & 120 & $2024-\mathrm{O}$ & 14 \\
11 & 120 & $2024-\mathrm{T} 3$ & 2 \\
12 & 120 & $6061-\mathrm{T} 4$ & 8 \\
13 & 140 & $2024-\mathrm{O}$ & 8 \\
14 & 140 & $2024-\mathrm{T} 3$ & 14 \\
15 & 140 & $6061-\mathrm{T} 4$ & 2 \\
16 & 160 & $2024-\mathrm{O}$ & 2 \\
17 & 160 & $2024-\mathrm{T} 3$ & 8 \\
18 & 160 & $6061-\mathrm{T} 4$ & 14 \\
\hline
\end{tabular}

A screening experiment based on the Taguchi L18 orthogonal array [9] has been carried out for each of the two composite core materials resulting in 36 experiments and is shown in Table 1.

A fractional factorial analysis generally allows one to use a definite metric to study the main effects of the different factors. For this study, due to the complex behaviour of the system and the difficulty of combining failure modes into a useable metric, a qualitative comparison is made to elucidate some understanding of the forming behaviour of the FML system.

\subsection{Laminate preparation}

Laminates were manufactured in a $2 / 1$ - aluminium/ composite configuration. The core layer consisted of either one $0.9 \mathrm{~mm}$ layer of self-reinforcing polypropylene (Curv, BP) or two 745 gsm layers of commingled 2:2 twill weave glass-fibre reinforced polypropylene prepreg (Twintex, Vetrotex). The skin layer consisted of a $0.5 \mathrm{~mm}$ aluminium sheet. Three grades of aluminium were chosen based on covering a wide range of material properties such as elongation and yield strength as shown in Table 2. Laminates of $200 \mathrm{~mm}$ square were produced by layering the aluminium and composite materials into a mould. A recommended hot-melt polypropylene adhesive sheet (Gluco) was used to bond the core and skin layers. The mould was placed into a pre-heated hot press with a thermocouple used to monitor the laminate temperature. Once the tem-

Table 2

Aluminium skin material properties

\begin{tabular}{lllll}
\hline Alloy & Specification & $\begin{array}{l}\text { Elongation } \\
(\%)\end{array}$ & $\begin{array}{l}\text { Yield } \\
\text { strength }(\mathrm{MPa})\end{array}$ & $\begin{array}{l}\text { Tensile } \\
\text { strength (MPa) }\end{array}$ \\
\hline 2024-O & QQ-A-250/5 & 18 & 75.8 & 186.2 \\
6061-T4 & QQ-A-250/11 & 22 & 144.8 & 241.3 \\
2024-T3 & QQ-A-250/5 & 16 & 344.7 & 482.6 \\
\hline
\end{tabular}




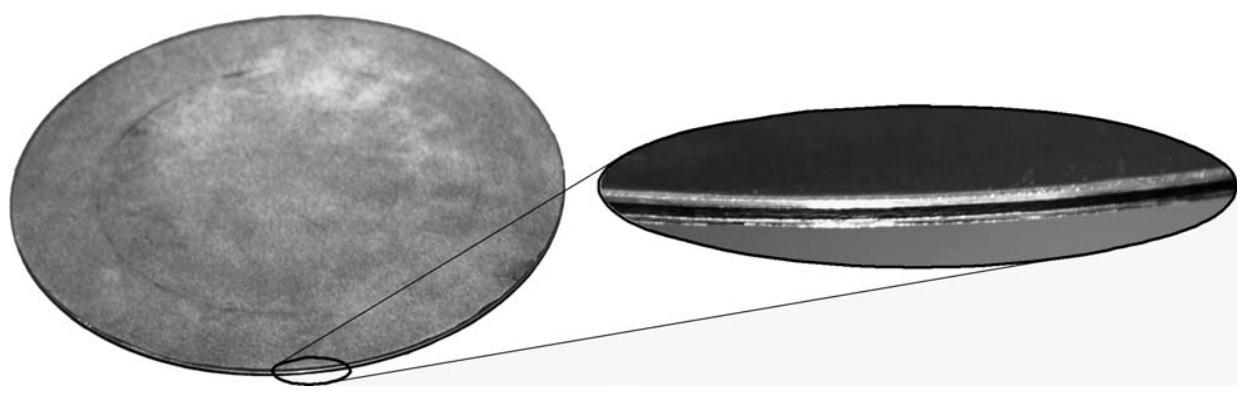

Fig. 1. Example of the prepared laminate blank and laminate edge.

perature of the laminate reached $160{ }^{\circ} \mathrm{C}$ the mould was transferred to a pneumatic press, a pressure of $0.5 \mathrm{MPa}$ was applied and the mould was allowed to cool to $40 \mathrm{C}$. The laminates were machined to $180 \mathrm{~mm}$ diameter discs using high-speed steel tooling on a lathe. Burrs were removed from the edge of the discs using a file. Fig. 1 shows an example of a prepared laminate blank.

\subsection{Stamp forming}

Draw forming of the laminates was achieved using a 30 tonne double action die press. The press consists of a feed rate controlled hydraulic ram and pressure controlled pneumatic blank-holder. Fig. 2 shows the press configuration using an open die of $105 \mathrm{~mm}$ diameter and a $100 \mathrm{~mm}$ diameter hemispherical dome punch. A compression load cell mounted in line with the punch measured forming loads while a linear potentiometer measured the punch displacement. Laminates were pre-heated to the desired temperature in a hot-press before being transferred to the stamping press. Alignment of the laminate was achieved using a $1 \mathrm{~mm}$ thick semi-circular template mounted to the die surface inline with the punch. Feed rate, blank-holder force, depth of draw, and cooling time were controlled through data acquisition hardware running under Labview on a local PC. Experiments were conducted at a feed rate of $20 \mathrm{~mm} / \mathrm{s}$ with a cooling time of $1 \mathrm{~min}$. Laminates were drawn until failure occurred, determined by a drop in the force-displacement curve of more than $2 \%$ of the maximum load.

\subsection{Evaluation of formability}

The following measures were used to assess the effects of process variables and constituent material properties on the forming behaviour of the FML systems.

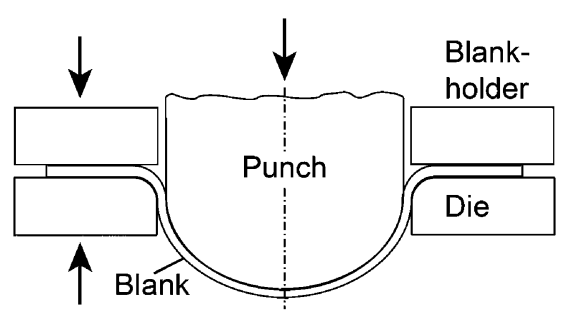

Fig. 2. Press configuration for hemispherical punch forming.

\subsubsection{Depth at failure}

The depth at which failure occurred within the forming process was measured from the punch force-displacement curve. This was used as a measure of the formability of a laminate. Only laminates that exhibited major failure by tearing or fracture are detectable in the punch force-displacement curve. When tearing or fracture occurs during forming there will be a release of energy and this can lead to a sharp drop in the punch force-displacement curve.

\subsubsection{Draw percentage}

The draw percentage defined in Eq. (1) is the percentage change of the final disc diameter $d$ to the original disc diameter $d_{\mathrm{O}}[10]$. The draw percentage is a direct measure of the successfulness of the blank to draw.

$D P=\frac{d_{\mathrm{O}}-d}{d_{\mathrm{O}}} \times 100 \%$

\subsubsection{Wrinkling}

The onset of wrinkling within a forming operation is difficult to predict and cannot be measured with the examination of the force-displacement curve. This makes it difficult to find a suitable measure for the severity of wrinkling and for this study, a subjective measure through observation was used to compare the severity of wrinkling between laminates.

\subsubsection{Delamination}

Typically, a measure of the severity of delamination is the quantity of area affected. In this study, a subjective measure through observation was used to compare the severity of delamination between laminates.

\section{Results and discussion}

\subsection{Effect of blank-holder force}

Observation of laminates formed at the highest and lowest blank-holder force provided an indication of the effect of blank-holder force on the formability of the FML system.

Fig. 3 shows runs formed at the lowest blank-holder force of $2 \mathrm{kN}$. The commonality between all laminates is the existence of wrinkling, indicating that a low 


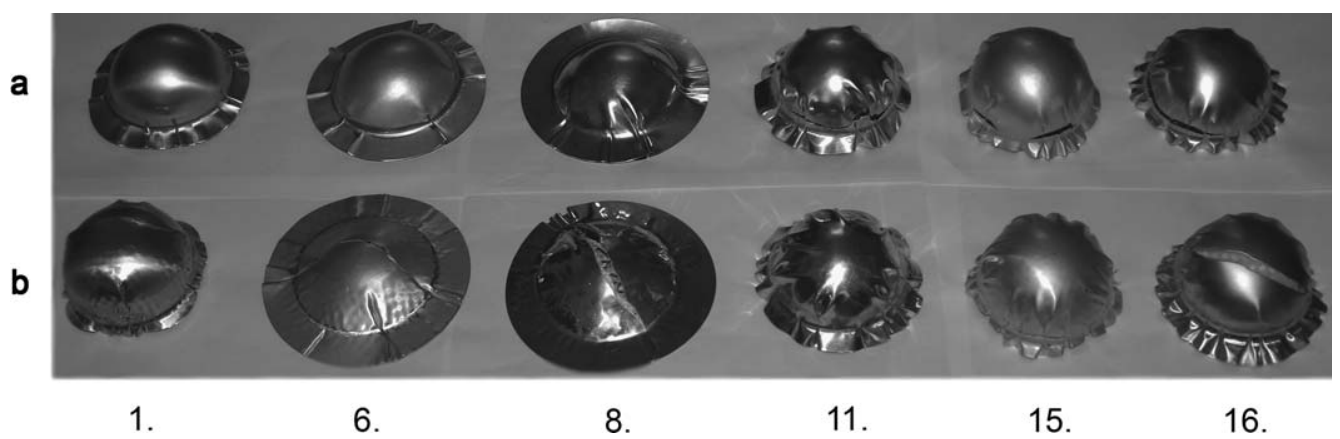

Fig. 3. Low blank-holder runs of the (a) Curv and (b) Twintex core material laminates.

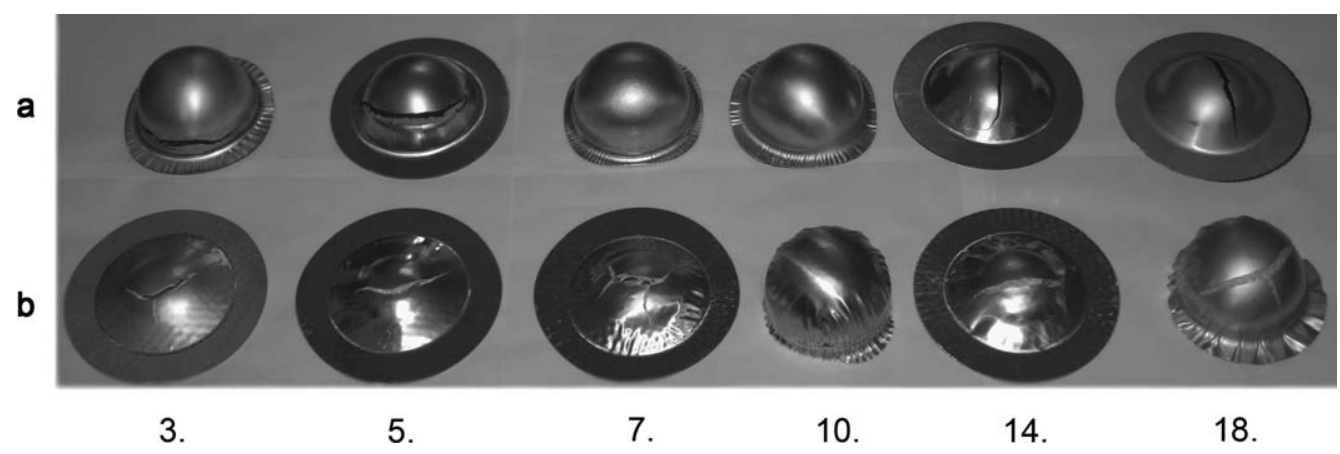

Fig. 4. High blank-holder runs of the (a) Curv and (b) Twintex core material laminates.

blank-holder force increases the likelihood of wrinkling as the main failure mode.

Fig. 4 shows runs formed at the highest blank-holder force of $14 \mathrm{kN}$. Ignoring the Twintex core runs of 10 and 18 , all laminates had very low or non-existent wrinkling in the flange. Laminates that failed had the tendency to fail due to tearing or fracture, indicating that a high blankholder force increases the tendency of failure due to tearing or fracture and decreases the likelihood of wrinkling. Curv composite core laminate runs 7 and 10 did not fail and reached the maximum draw depth of $70 \mathrm{~mm}$. Twintex laminate runs 10 and 18 had a significant amount of wrinkling in the sidewall and flange areas, run 14 for both cores showed some wrinkling in the sidewall. These laminates do not obey the general trend of the other laminates formed under a high blank-holder force, however, runs 10, 14, and 18 were formed at elevated temperatures of 120,140 , and $160{ }^{\circ} \mathrm{C}$ respectively. This high preheat temperature may have increased the tendency of wrinkling failure.

This general behaviour of the blank-holder force effecting the failure mode is typical in draw forming of monolithic metals were the draw depth is limited by the onset of wrinkling or fracture. This study indicates that the blank-holder force is a limiting factor in the stamp forming of FML systems.

\subsection{Effect of core and skin material}

To investigate the effect of core and skin material on the formability of FML systems the draw depth, draw percentage, and punch force of runs 3,5 , and 7 were analysed. These laminates were formed under a $14 \mathrm{kN}$ blankholder and as such, there main failure mode was tearing or fracture. Fig. 5 shows the six combinations of the three aluminium skin layers and the two composite cores.

Table 3 shows the measured draw depth and draw percentage for these laminates. For both types of core material, the fully annealed 2024 showed the best draw depth and draw percentage while 2024-T3 showed the least ability to draw. The 6061-T4 aluminium alloy showed much better formability combined with the Curv composite core than it did with the Twintex core.

The most obvious observation is the effect of the core material. The Curv core and skin material combinations had far better drawing characteristics than the Twintex core based FMLs. All three combinations of aluminium with a Twintex core failed due to tearing in the centre region of the disc. This failure type is characteristic of failure due to biaxial stretch over the punch. Further research is needed to determine whether the material failed due to its inability to withstand biaxial strain or due to the materials inability to draw causing severe levels of biaxial stress.

Figs. 6 and 7 show the punch force-displacement curves measured during forming of runs 3,5 , and 7 for each composite core. These curves show that the loads needed to form the FML system is highly dependent on the skin material chosen. This increase in force may be due to the differences in yield strength of the skin material. The force required to draw material into the die cavity will be dependent on the flow stress of the material, higher material yield 


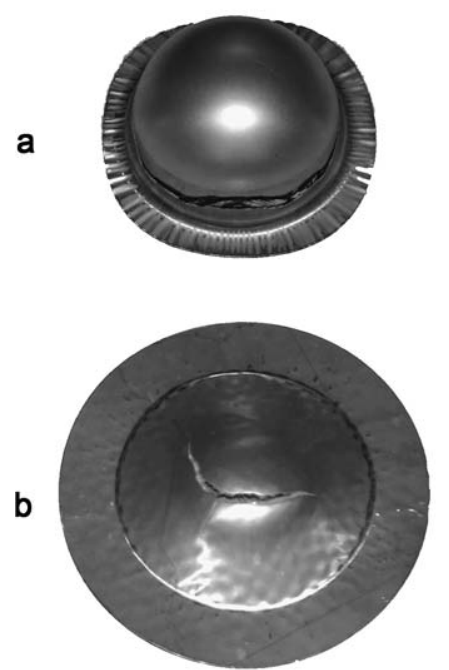

3. $(6061-\mathrm{T} 4)$
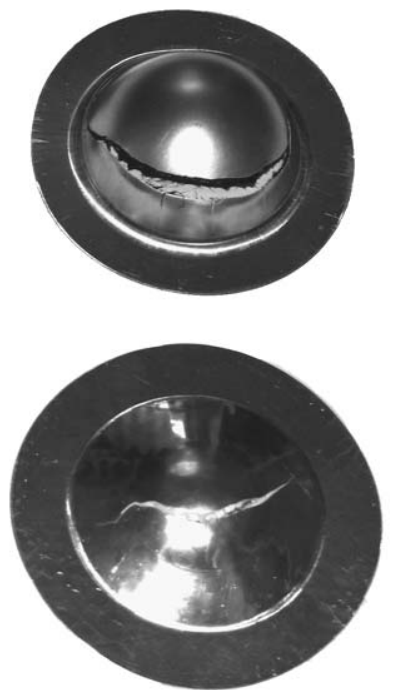

5. (2024-T3)
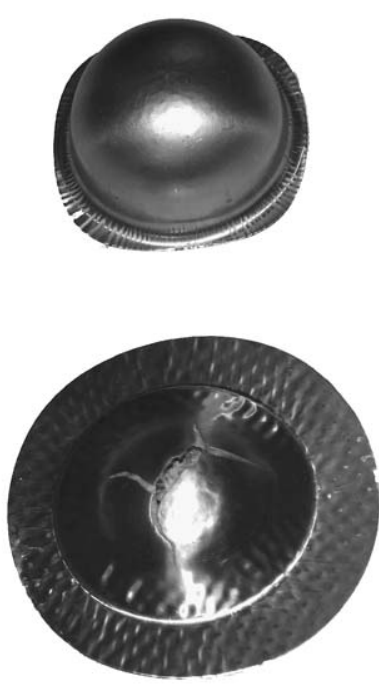

7. (2024-O)

Fig. 5. Runs 3, 5, and 7 with aluminium layers of 6061-T4, 2024-T3, and 2024-O respectively for (a) Curv and (b) Twintex laminates.

Table 3

Draw depths and draw percentages for runs 3,5 , and 7 for each composite core

\begin{tabular}{llll}
\hline $\begin{array}{l}\text { Core } \\
\text { material }\end{array}$ & $\begin{array}{l}\text { Skin } \\
\text { material }\end{array}$ & $\begin{array}{l}\text { Draw depth at } \\
\text { failure }(\mathrm{mm})\end{array}$ & $\begin{array}{l}\text { Draw } \\
\text { percentage }\end{array}$ \\
\hline Curv & $2024-\mathrm{O}$ & 70 & 27 \\
& $6061-\mathrm{T} 4$ & 67.6 & 22.2 \\
& $2024-\mathrm{T} 3$ & 52.7 & 8.3 \\
Twintex & $2024-\mathrm{O}$ & 27.6 & 2.8 \\
& $6061-\mathrm{T} 4$ & 23 & 1.7 \\
& $2024-\mathrm{T} 3$ & 22.6 & 1.7 \\
\hline
\end{tabular}

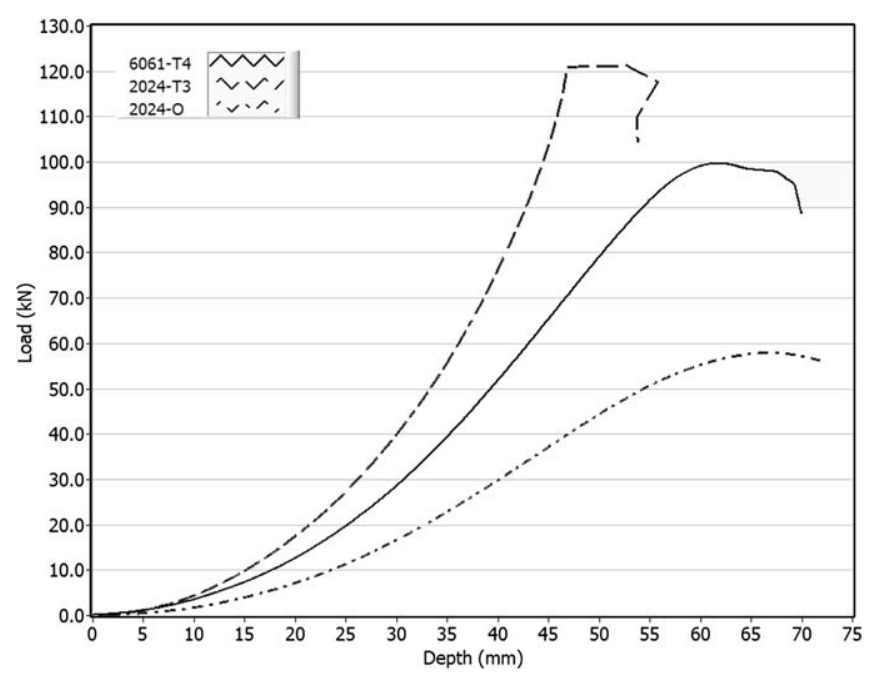

Fig. 6. Punch force-displacement curve for Curv based runs 3, 5, and 7.

strength would result in higher draw forces. It is desirable in most forming applications to keep forming forces to a minimum to reduce tool wear and costs.

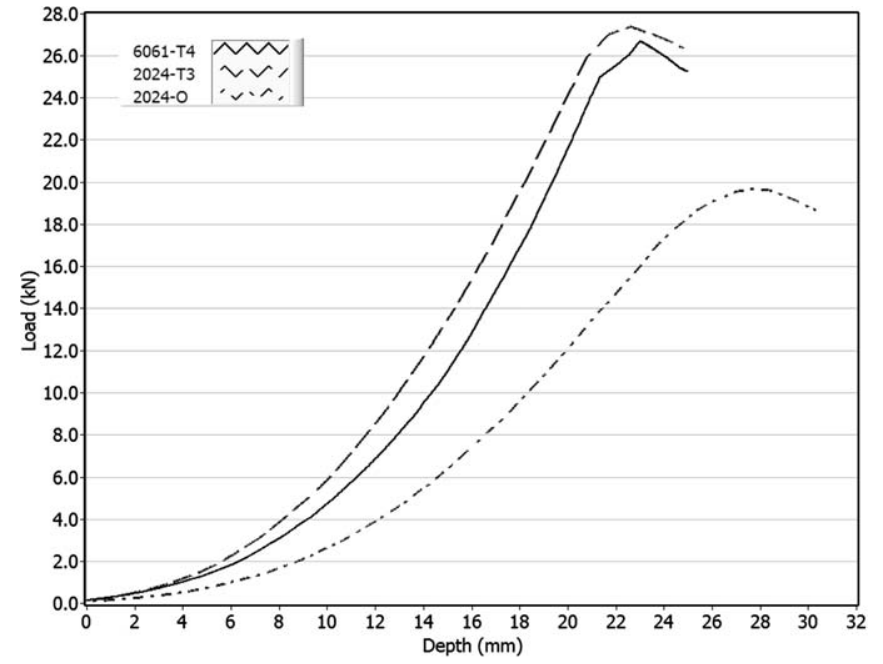

Fig. 7. Punch force-displacement curve for Twintex based runs 3, 5, and 7.

Fig. 8 shows an example of the difference between the magnitudes of force required to form the 2024-O/Curv and 2024-O/Twintex based FML systems. The Twintex FML requires higher forming loads to achieve the same depth than the Curv based FML. For example, an $18.3 \mathrm{kN}$ load is required to form the 2024-O/Twintex based FML to a depth of $25 \mathrm{~mm}$ while the 2024-O/Curv based FML requires $11.4 \mathrm{kN}$.

\subsection{Effect of preheat temperature}

It was observed that the effect of preheat temperature on the formability of an FML was highly dependent on the core material and blank-holder force. To investigate the effect of preheat temperature at low blank-holder force runs 6 and 15 were analysed. Fig. 9 shows the effect of a 


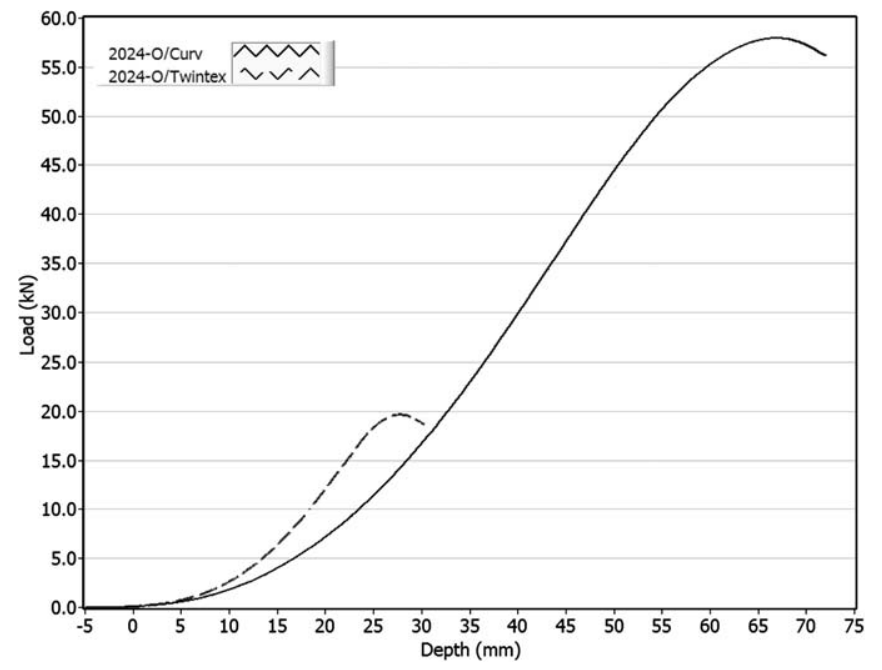

Fig. 8. Punch force-displacement curve between a 2024-O/Curv and 2024$\mathrm{O} /$ Twintex FML.
$60{ }^{\circ} \mathrm{C}$ preheat temperature and a $140{ }^{\circ} \mathrm{C}$ preheat temperature on the formability of the Curv and Twintex FMLs under a $2 \mathrm{kN}$ blank-holder force. The increase in temperature caused a significant increase in the severity of wrinkling for both core material types.

Fig. 10 shows the severity of the wrinkling and delamination of the laminates. At a high preheat temperature the severity of delamination is significantly increased within the outer flange and is most likely caused by the increased wrinkling.

To investigate the effect of preheat temperature at high blank-holder force runs 5 and 15 were analysed. Fig. 11 is an example of how the preheat temperature affects the formability at high blank-holder forces. Laminates were formed at $60{ }^{\circ} \mathrm{C}$ and $140{ }^{\circ} \mathrm{C}$ under a $14 \mathrm{kN}$ blank-holder force. Table 4 presents the change in draw depth and draw percentage for these laminates. It indicates that increasing the preheat temperature for a Curv based FML system
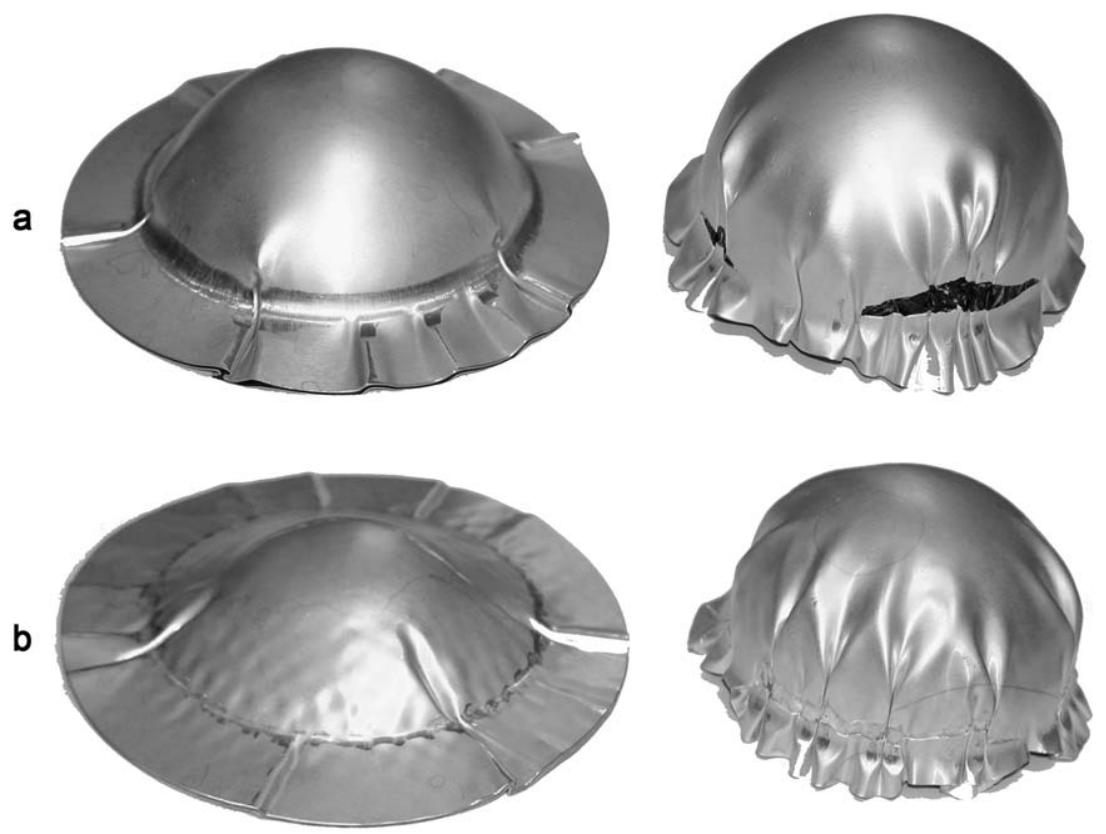

6. $\left(60^{\circ} \mathrm{C}\right)$

15. $\left(140^{\circ} \mathrm{C}\right)$

Fig. 9. Effect of preheat temperature under low blank-holder force for (a) Curv and (b) Twintex runs 6 and 15.

a

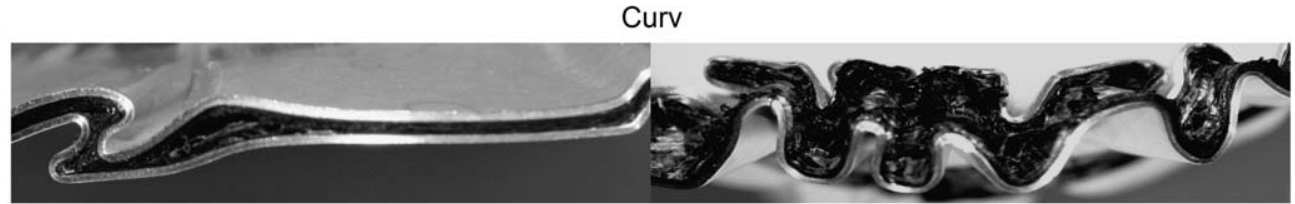

Twintex

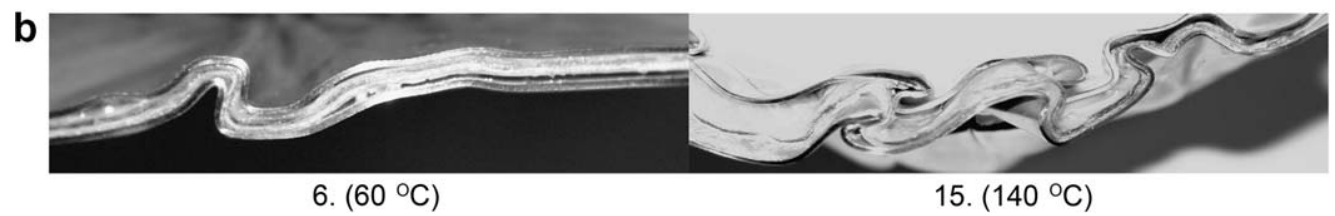

Fig. 10. Severity of wrinkling and delamination due to preheat temperature for (a) Curv and (b) Twintex runs 6 and 15. 


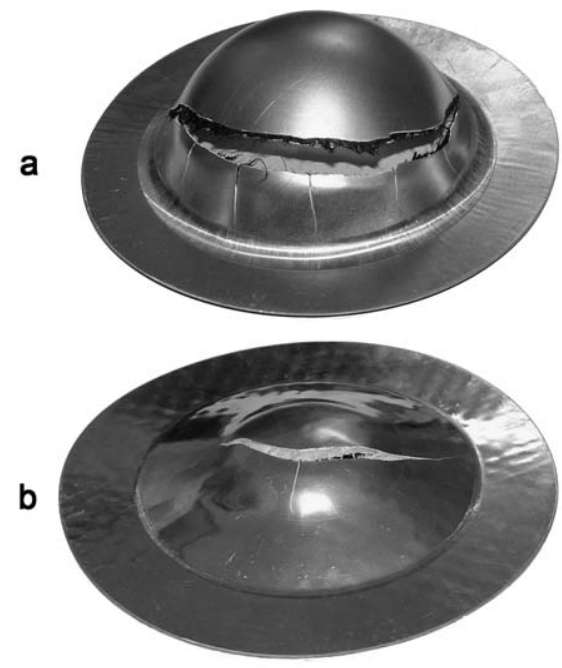

5. $\left(60^{\circ} \mathrm{C}\right)$

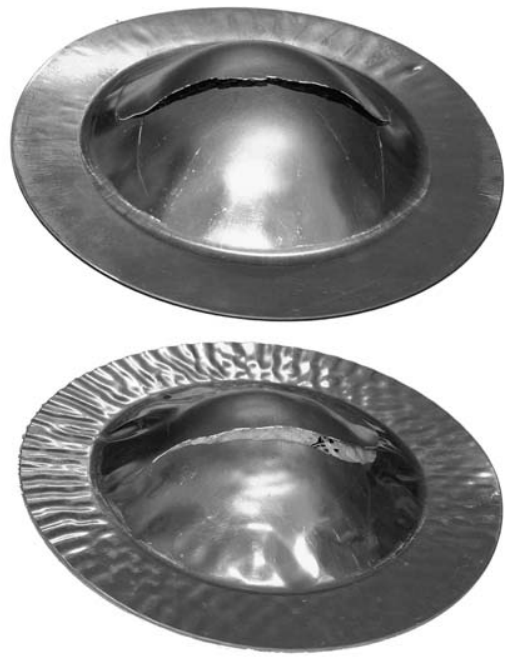

14. $\left(140^{\circ} \mathrm{C}\right)$

Fig. 11. Effect of preheat temperature under high blank-holder force for (a) Curv and (b) Twintex runs 5 and 14.

Table 4

Draw depth and draw percentage of runs 5 and 14

\begin{tabular}{llll}
\hline $\begin{array}{l}\text { Preheat } \\
\text { temperature }\left({ }^{\circ} \mathrm{C}\right)\end{array}$ & $\begin{array}{l}\text { Core } \\
\text { material }\end{array}$ & $\begin{array}{l}\text { Draw depth } \\
\text { at failure }(\mathrm{mm})\end{array}$ & $\begin{array}{l}\text { Draw } \\
\text { percentage }\end{array}$ \\
\hline 60 & $\begin{array}{l}\text { Curv } \\
\text { Twintex }\end{array}$ & 52.7 & 8.3 \\
& 27.6 & 2.8 \\
140 & Curv & 36.4 & 3.9 \\
& Twintex & 29.1 & 3.1 \\
\hline
\end{tabular}

has an adverse effect on its formability, while for a Twintex based FML it has a positive effect.

It is noticed that the amount of sidewall wrinkling has increased in both core material type FMLs when the preheat temperature is increased. This indicates a strong interaction effect between the blank-holder force required to prevent wrinkling and the preheat temperature used.

The failure of the Curv and Twintex at low temperature/ high blank-holder shows all three laminate layers are damaged. At high temperature, the Curv based FML fails only in the two aluminium skin layers with the composite core remaining intact. The Twintex FML had a similar failure at high preheat temperature. However, some damage to the core layer was sustained but was significantly less than at low temperatures. This indicates that high temperature forming can decrease the failure in the core composite material for both the Curv and Twintex FML systems.

\section{Conclusion}

In this paper, the drawing behaviour of metal-composite sandwich structures is described. An inspection of the relevant failure modes produced by the material composition and processes variables is important in defining the optimal forming window for these hybrid material systems. Screening experiments have shown that the blank-holder force has a significant effect on the failure mode exhibited by the FML system, with lower forces resulting in wrinkling and higher forces resulting in tearing and fracture. An important observation was the effect of the preheat temperature. Increasing the preheat temperature had a positive effect in decreasing the severity of failure in the composite core. However, the increase in preheat temperature caused an increase in the severity of wrinkling in the outer flange and sidewall. This indicates a high interaction between the preheat temperature and the blank-holder force required to suppress wrinkling. Further work will focus on using a real time strain measurement technique to map the strain distribution during forming. This in turn will provide a mechanics approach to correlate the failure behaviour with effect of the material system and process variables.

\section{References}

[1] Vlot A, Vogelesang LB, de Vries TJ. Fibre metal laminates for high capacity aircraft. In: 30th international SAMPE technical conference, San Antonio, October 1998. p. 456-70.

[2] Mosse L, Cantwell W, Cardew-Hall M, Compston P, Kalyanasundaram S. Effect of process temperature and blank-holder force on the forming of fibre metal laminate systems. In: Proceedings of 11th European conference on composite materials, Rhodes, 2004.

[3] Mosse L, Cantwell W, Cardew-Hall M, Compston P, Kalyanasundaram S. The effect of process temperature on the formability of polypropylene based fibre-metal laminates. In: Composites Part A vol. 36, 2005. p. 1158-66.

[4] Mosse L, Cantwell W, Cardew-Hall M, Compston P, Kalyanasundaram S. Forming characteristics of aluminium and glass-reinforced thermoplastic fibre-metal laminates. In: Proceedings of the AsianAustralian conference in composite materials, Sydney, 2004. p. 852-7.

[5] Mosse L, Cantwell W, Cardew-Hall M, Compston P, Kalyanasundaram S. Investigation of process temperature on the cup forming of fibre-metal-laminate systems. SHEMet, 2005.

[6] Kim JK, Thomson PF. Forming behaviour of sheet steel laminate. J Mater Process Tech 1990;22:44-64. 
[7] Bogaerts L, Lossie M, Vandepitte D, Deepdrawing of composite sheet materials. In: Proceedings of the 9th international conference on sheet metal. Leuven, 2001. p. 127-34.

[8] Friedrich K, Hou M. On stamp forming of curved and flexible geometry components from continuous glass fiber/polypropylene composites. Composites Part A 1998;29:216-7.
[9] Fowlkes WY, Creveling CM. Engineering methods for robust product design: using Taguchi methods in technology and product development. Addison and Wesley; 1995.

[10] Marciniak Z, Duncan JL, Hu SJ. Mechanics of sheet metal forming. Butterworth-Heinemann; 2002. 